\title{
Effects of mitotane on the hypothalamic- pituitary-adrenal axis in patients with adrenocortical carcinoma
}

\author{
Giuseppe Reimondo', Soraya Puglisi², Barbara Zaggia', Vittoria Basile', Laura Saba', Paola Perotti', \\ Silvia De Francia ${ }^{3}$, Marco Volante ${ }^{4}$, Maria Chiara Zatellí ${ }^{5}$, Salvatore Cannavò ${ }^{2}$ and Massimo Terzolo ${ }^{1}$
}

${ }^{1}$ Internal Medicine 1, Department of Clinical and Biological Sciences, University of Turin, Orbassano, Italy, ${ }^{2}$ Endocrine Unit, Department of Clinical and Experimental Medicine, University of Messina, Messina, Italy, ${ }^{3}$ Pharmacology, Department of Clinical and Biological Sciences and ${ }^{4}$ Pathology, Department of Oncology, University of Turin, Orbassano, Italy, and ${ }^{5}$ Section of Endocrinology and Internal Medicine, Department of Medical Science, University of Ferrara, Ferrara, Italy

Correspondence should be addressed to S Puglisi

Email

sorayapuglisi@yahoo.it

\begin{abstract}
Objective: Mitotane, a drug used to treat adrenocortical cancer (ACC), inhibits multiple enzymatic steps of adrenocortical steroid biosynthesis, potentially causing adrenal insufficiency. Recent studies in vitro have also documented a direct inhibitory effect of mitotane at the pituitary level. The present study was aimed to assess the hypothalamic-pituitary-adrenal axis in patients with ACC receiving mitotane.

Design and methods: We prospectively enrolled 16 patients on adjuvant treatment with mitotane after radical surgical resection of ACC, who underwent standard hormone evaluation and h-CRH stimulation. A group of 10 patients with primary adrenal insufficiency (PAI) served as controls for the CRH test.

Results: We demonstrated a close correlation between cortisol-binding globulin (CBG) and plasma mitotane levels, and a non-significant trend between mitotane dose and either serum or salivary cortisol in ACC patients. We did not find any correlation between the dose of cortisone acetate and either ACTH or cortisol levels. ACTH levels were significantly higher in patients with PAI than that in patients with ACC, both in baseline conditions (88.99 (11.04-275.00) vs 24.53 (6.16-121.88) pmol/L, $P=0.031$ ) and following CRH (158.40 (34.32-275.00) vs $67.43(8.8-179.52) \mathrm{pmol} / \mathrm{L} P=0.016)$. Conclusions: The observation of lower ACTH levels in patients with ACC than that in patients with PAI, both in basal conditions and after CRH stimulation, suggests that mitotane may play an inhibitory effect on ACTH secretion at the pituitary levels. In conclusion, the present study shows that mitotane affects the HPA axis at multiple levels and no single biomarker may be used for the assessment of adrenal insufficiency.
\end{abstract}

\section{Introduction}

Mitotane has been used in the treatment of adrenocortical cancer (ACC) over the last 50 years and is generally regarded as a toxic drug with a narrow therapeutic index $(1,2,3,4,5,6)$. It is well known that mitotane is able to inhibit multiple enzymatic steps of adrenocortical steroid biosynthesis and for this reason mitotane has been used to treat Cushing's syndrome of different etiologies (7). After the demonstration that adjunctive mitotane treatment

www.eje-online.org DOI: 10.1530/EJE-17-0452
() 2017 European Society of Endocrinology Printed in Great Britain following radical extirpation of ACC extends disease-free survival (8), mitotane has been increasingly used in an adjuvant post-operative setting $(9,10,11,12)$.

It is anticipated that patients who had adjuvant mitotane treatment may develop adrenal insufficiency; thus, some clinicians prefer to initiate cortisol replacement concomitantly with mitotane $(10,12)$. However, there is still limited knowledge on the impact of chronic mitotane 
treatment on the function of the hypothalamic-pituitaryadrenal (HPA) axis. Since ACC is a very rare and aggressive tumor, the available studies did not focus on the consequences of chronic treatment with mitotane, but the issue of the mitotane-induced impairment of adrenal function is clinically relevant due to the improved prognosis of patients managed in referral centers following surgical removal of ACC $(9,11,13)$. An obvious goal of steroid replacement is to avoid an adrenal crisis that may be difficult to recognize because symptoms of adrenal insufficiency mimic mitotane toxicity (e.g. asthenia, nausea) $(14,5)$. Although it is wise to err in favor of over-replacement, these patients should be spared from the complications of excessive steroid treatment; a challenging aim due to the usual practice of giving high doses of steroids in mitotane-treated patients. The rationale for this stands in the cytochrome P4503A4 induction by mitotane that results in rapid and massive inactivation of administered hydrocortisone (15).

We had previously investigated the effects of mitotane on the endocrine system in patients treated adjunctively after complete ACC removal (16), showing that the drug was able to impair adrenal hormone secretion and to increase cortisol-binding globulin (CBG). ACTH levels were found to be scattered with great individual variations. More recently, Gentilin et al. (17) showed that mitotane was able to affect corticotroph function and cell survival in the mouse pituitary cell line AtT20/D16v-F2 and in the primary cultures of human ACTH-secreting pituitary adenomas. Mitotane reduced cell viability and ACTH secretion by blocking the stimulatory effects of corticotropin releasing hormone (CRH) on cell viability, ACTH secretion and POMC expression. These effects were apparent at mitotane doses greater than those usually necessary for reducing cortisol secretion in Cushing's syndrome, but still in the therapeutic range for ACC treatment. This study coupled with previous evidence that mitotane was able to impair thyrotrope cell viability, TSH secretory activity, TSH expression and TRH responsivity in T-T1 cells (18), supports the hypothesis that mitotane may have direct inhibitory effects at the pituitary level.

Here, we did a comprehensive assessment of the HPA axis in patients receiving mitotane as adjuvant treatment after radical resection of ACC to get insights on the pathophysiology of the HPA axis in this condition looking for markers of potential clinical interest.

\section{Subjects and methods}

For the purpose of this study, we enrolled prospectively 16 consecutive patients who were managed at our center for adjuvant mitotane treatment between 2013 and 2015 . Patients had radical (R0) resection of ACC, performed at least 1 year before (median 41 months) and followed by adjuvant mitotane treatment for at least 1 year (median 31 months). This series was homogeneous and representative of patients in mitotane adjuvant treatment. All patients were on a program of regular follow-up at our center.

Patients were on stable mitotane dose and steroid supplementation for at least 6 months and were disease free at the time of evaluation. The institutional ethics committee of our hospital approved the study, and all patients provided written informed consent.

Inclusion criteria for the study were: age $\geq 18$ years, pathologically confirmed diagnosis of ACC (diagnoses were done or confirmed by the pathologists of San Luigi Hospital), availability of pre-operative and postoperative computed tomography (CT) scans, ACC stage I-III at diagnosis, R0 resection of primary tumor, complete follow-up information. Exclusion criteria were: incomplete tumor staging, ENSAT stage IV, history of other previous/concomitant malignancies, $\mathrm{Rx}$ or $\mathrm{R} 1$ resection, follow-up of less than 12 months or incomplete follow-up information.

All patients received the same mitotane formulation (Lysodren, $500 \mathrm{mg}$ tablets) orally at a starting dose of $1 \mathrm{~g}$ daily, with progressive weekly increments up to 4-6g daily, or the highest tolerated dose, aiming to reach concentrations between 14 and $20 \mathrm{mg} / \mathrm{L}$ (19). When such or even higher concentrations were attained, doses were tapered with further individual dose adjustments guided by the results of mitotane measurement and toxicity assessment. From the time mitotane was commenced, all the patients received glucocorticoid replacement with a two-dose regimen of cortisone acetate (2/3 of dose in the morning at awakening, $1 / 3$ of dose in the early afternoon). Due to the well-known enhanced metabolic clearance rate of glucocorticoids induced by mitotane (15), cortisone acetate was given at doses much higher than that in Addison's disease. The dose of cortisone acetate was adjusted during mitotane treatment based on careful clinical assessment, according to our standard practice (14).

A group of 10 patients with primary adrenal insufficiency served as controls for the CRH test. In five patients hypoadrenalism had an autoimmune origin (Addison's disease), whereas in five patients it was due to bilateral adrenalectomy done in patients with previous Cushing's syndrome caused by ectopic ACTH-secreting tumors, which were found and radically removed after adrenalectomy. 


\section{Study protocol}

The study was done in an outpatient setting. A CRH test was performed between 08:30 and 09:00 h, after an overnight fast and omitting any hormone replacement in the morning. We deliberately set a minimum interval of $12 \mathrm{~h}$ after the last dose of cortisone acetate. An antecubital vein was cannulated $30 \mathrm{~min}$ before the beginning of the test and blood samples were taken for measurement of plasma ACTH and serum cortisol at $-15,0,15,30,45$ and 60 after injection of human CRH (Ferring Arzneimittel GesmbH, Wien, Austria; $100 \mu \mathrm{g}$ as an intravenous bolus). The patients with ACC also underwent routine laboratory evaluation, monitoring of mitotane concentrations and a hormonal work-up including determination of morning salivary cortisol, dehydroepiandrosterone sulfate (DHEAS), aldosterone, plasma renin activity (PRA) and cortisol-binding globulin (CBG). In patients with ACC, ACTH and cortisol levels were measured in the previous 12 months (a minimum of 6 measurements) and their correlations with supplemental glucocorticoid dose were analyzed. Patients with PAI underwent only a CRH test. Blood samples for serum and plasma hormone analyzes were collected in tubes that did not contain any additives or contained K2-EDTA, respectively. The serum was obtained by centrifuging the tubes at $3000 \mathrm{rpm}$ for $15 \mathrm{~min}$ at room temperature, whereas the plasma was obtained by centrifuging the tubes at $3000 \mathrm{rpm}$ for $15 \mathrm{~min}$ at $4^{\circ} \mathrm{C}$. After separation from the red blood cells, serum and plasma were stored at $4-8^{\circ} \mathrm{C}$ if the assays were performed within $24 \mathrm{~h}$ while, for longer storage periods, they were aliquoted and frozen at $-20^{\circ} \mathrm{C}$ until assayed. Saliva was collected by chewing a cotton swab (Salivette, Sarstedt, Nümbrecht, Germany) over a 1-3 min period, centrifuged at $2000 \mathrm{rpm}$ for $10 \mathrm{~min}$, aliquoted and frozen at $-20^{\circ} \mathrm{C}$. Hormones were measured in-house with commercially available reagents. Serum cortisol and serum DHEAS were measured using competitive chemiluminescent enzyme immunoassay (Immulite 2000, DPC, Los Angeles, CA, USA). The following hormones were measured using radioimmunoassay (RIA): salivary cortisol (Radim, Pomezia, Rome, Italy), PRA (Sorin Biomedica, Saluggia, Italy), Aldosterone (Adaltis, Bologna, Italy), CBG (DIAsource, Ottignies Louvain la Neuve, Belgium). ACTH was measured with immunoradiometric assay (IRMAScantibodies Laboratory Inc., Santee, USA). The normal range and the detection limit of the different assays used in hormone monitoring were reported in Table 1. Intraand inter-assay coefficients of variation for all hormone variables, performed in duplicate, were less than $5 \%$ and $9 \%$, respectively. Plasma mitotane was measured in-house by a HPLC assay, as described previously (20). Routine clinical chemistry variables were determined using standard enzymatic methods.

\section{Statistical analysis}

All statistical analyses were performed using Statistica (StatSoft) statistical software. For each patient, net and percentage ACTH and cortisol increments from baseline following CRH for both ACTH and cortisol were

Table 1 Hormonal data of patients with ACC.

\begin{tabular}{|c|c|c|c|}
\hline Characteristics & Values, median (range) & Normal range & Detection limit \\
\hline Serum cortisol (nmol/L) & $42.49(13.80-460.75)$ & $248.31-689.75$ & 13.80 \\
\hline Salivary cortisol (nmol/L) & $4.97(2.80-14.35)$ & $13.80-27.60$ & 2.80 \\
\hline Plasma ACTH (pmol/L) & $24.53(6.16-121.88)$ & $1.32-13.20$ & 1.10 \\
\hline Serum CBG $(\mu \mathrm{mol} / \mathrm{L})$ & $2.92(0.94-3.90)$ & & 0.01 \\
\hline Males & & $0.42-1.04$ & \\
\hline Females & & $0.76-2.91$ & \\
\hline Plasma PRA $(\mu \mathrm{g} / \mathrm{L} / \mathrm{h})$ & $1.80(0.60-5.10)$ & $0.80-6.00$ & 0.20 \\
\hline Serum Aldosterone (nmol/L) & $0.33(0.18-0.66)$ & $0.14-0.80$ & 0.02 \\
\hline Serum DHEAS $(\mu \mathrm{mol} / \mathrm{L})$ & $<0.41$ & & 0.41 \\
\hline \multicolumn{4}{|l|}{ Males } \\
\hline 30-39 years & & $2.99-10.04$ & \\
\hline 40-49 years & & $1.22-9.36$ & \\
\hline $50-59$ years & & $0.68-6.51$ & \\
\hline 60-69 years & & $0.68-2.58$ & \\
\hline \multicolumn{4}{|l|}{ Females } \\
\hline 40-49 years & & $0.68-5.97$ & \\
\hline 50-59 years & & $0.41-4.61$ & \\
\hline $60-69$ years & & $<5.02$ & \\
\hline 70-90 years & & $<2.44$ & \\
\hline
\end{tabular}


calculated. Rates and proportions were calculated for categorical data and medians and ranges for continuous data. Differences were analyzed by means of the chisquare test, Fisher's exact test and Mann-Whitney $U$ test. Correlation analyses were determined by calculating the Spearman's $R$ coefficient. $P$ values of less than 0.05 were considered to indicate statistical significance.

\section{Results}

The group of ACC patients included 10 men and 6 women, aged between 35 and 70 years (median: 52 years). Their baseline characteristics are provided in Table 2. At the time of the study, 6 patients had mitotane levels within the therapeutic range $(14-20 \mathrm{mg} / \mathrm{L})$ (19) and 1 had mitotane levels $>20 \mathrm{mg} / \mathrm{L}$, whereas 9 had mitotane levels $<14 \mathrm{mg} / \mathrm{L}$ ( $<10 \mathrm{mg} / \mathrm{L}$ in 5 cases). The median dose of cortisone acetate was $62.5 \mathrm{mg}$ daily (range: $50-100 \mathrm{mg}$ daily), corresponding to $33.1 \mathrm{mg} / \mathrm{m}^{2}$ of body surface $\left(24.9-50.4 \mathrm{mg} / \mathrm{m}^{2}\right)$ or $0.8 \mathrm{mg} / \mathrm{kg}(0.6-1.2 \mathrm{mg} / \mathrm{kg})$.

The group of patients with PAI included 4 men and 6 women, aged between 32 and 63 years (median: 54.5 years). In this group, the median dose of cortisone acetate was $31.25 \mathrm{mg}$ daily (range: $18.75-37.5 \mathrm{mg}$ ), corresponding to $15.9 \mathrm{mg} / \mathrm{m}^{2}$ of body surface $\left(9.9-19.6 \mathrm{mg} / \mathrm{m}^{2}\right)$ or $0.42 \mathrm{mg} / \mathrm{kg}(0.25-0.51 \mathrm{mg} / \mathrm{kg})$.

Hormonal data of the patients with ACC are provided in Table 1. Basal serum cortisol was reduced in 14 (87.5\%) patients, remained undetectable in 7 (43.8\%) of them, and was in the normal range in only $2(12.5 \%)$ patients; one of them had low mitotane concentrations. Basal salivary cortisol was reduced in $14(87.5 \%)$ patients, remained undetectable in 8 (50.0\%) of them, and was in the normal range in only 2 patients (the same cases as above). Only a non-significant trend between mitotane dose and either serum cortisol (Fig. 1) or salivary cortisol was evident. However, 9 of 11 patients with cortisol $<100 \mathrm{nmol} / \mathrm{L}$ showed persistently elevated levels of mitotane (in the target range) for at least 12 months preceding the study. Plasma ACTH levels were elevated in 11 (68.7\%) patients and normal in $5(31.3 \%)$ patients. ACTH levels were not correlated with either plasma mitotane concentrations (Fig. 2) or serum or salivary cortisol. Median CBG levels were of $2.92 \mu \mathrm{mol} / \mathrm{L}(0.94-3.90)$ being supranormal in 11 (68.7\%) patients, whereas DHEAS levels were undetectable $(<0.4 \mu \mathrm{mol} / \mathrm{L})$ in all patients. CBG levels were positively correlated with plasma mitotane concentrations $(\mathrm{r}=0.80$, $P=0.003)$. Only one patient was on mineralocorticoid replacement and the remainders had normal PRA (1.80,
Table 2 Baseline characteristics of patients with ACC.

\begin{tabular}{|c|c|}
\hline Characteristics & $\begin{array}{c}\text { ACC patients } \\
\quad(n=16)\end{array}$ \\
\hline Age (years) & $53.5(35-70)$ \\
\hline \multicolumn{2}{|l|}{$\operatorname{Sex}(n(\%))$} \\
\hline Men & $10(62.5 \%)$ \\
\hline Women & $6(37.5 \%)$ \\
\hline \multicolumn{2}{|l|}{ Functional status ( $n(\%))$} \\
\hline Overt Cushing & $2(12.5 \%)$ \\
\hline Subclinical Cushing & $3(18.75 \%)$ \\
\hline Non-functional tumors & $11(68.75 \%)$ \\
\hline Duration of adjuvant mitotane (months) & $31(12-63)$ \\
\hline Plasma mitotane levels (mg/L) & $13.5(5.7-24.3)$ \\
\hline Mitotane dose (g/day) & $2.0(1.0-4.5)$ \\
\hline Cortisone acetate dose (mg/day) & $62.5(50-100)$ \\
\hline Cortisone acetate dose $\left(\mathrm{mg} / \mathrm{m}^{2} /\right.$ day $)$ & $33.1(24.9-50.4)$ \\
\hline Cortisone acetate dose (mg/kg/day) & $0.8(0.6-1.2)$ \\
\hline
\end{tabular}

$0.60-5.10 \mu \mathrm{g} / \mathrm{L} / \mathrm{h})$ and aldosterone levels $(0.33,0.18$ $0.66 \mathrm{nmol} / \mathrm{L})$. ACTH and cortisol levels measured in the previous 12 months did not show any correlation with glucocorticoid dose in use at the time of sampling.

After CRH challenge, the median value of the net ACTH increment was $14.81 \mathrm{pmol} / \mathrm{L}$ (1.94-39.49) and the median value of percent ACTH increment was $85 \%$ ( -7 to $512)$; whereas the net cortisol increment was $41.38 \mathrm{nmol} / \mathrm{L}$ (13.79-402.81), and the percent cortisol increment was $0 \%$ ( -35 to 246 ). The 2 patients with normal baseline cortisol levels showed no cortisol response to $\mathrm{CRH}$ whereas ACTH levels were elevated in one case and normal in the other and responding to $\mathrm{CRH}$ in both cases. An ACTH increment $>35 \%$ was observed in $13(81.2 \%)$ patients whereas only 3 $(18.8 \%)$ patients had a cortisol increment $>20 \%$, however, with negligible absolute values $(<82.77 \mathrm{nmol} / \mathrm{L})$. ACTH levels were significantly higher in patients with PAI than

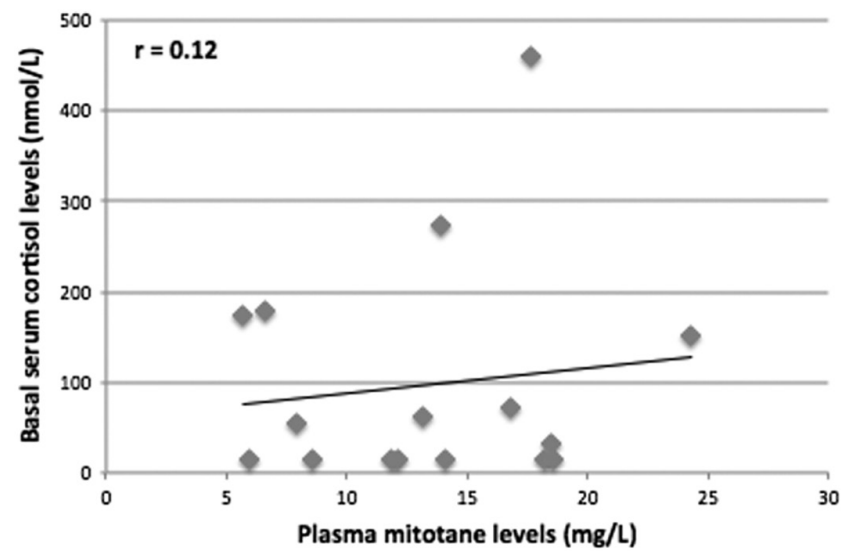

Figure 1

Correlation between morning serum cortisol levels and plasma mitotane levels in patients with ACC. $r=$ correlation coefficient. 


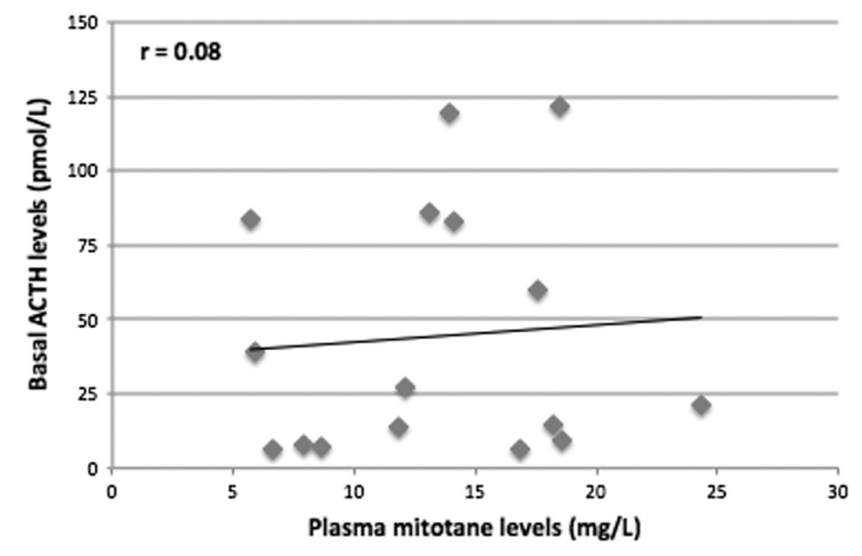

Figure 2

Correlation between basal ACTH levels and plasma mitotane levels in patients with ACC. $r=$ correlation coefficient.

that in patients in ACC, both in baseline conditions (88.99 (11.04-275.00) vs 24.53 (6.16-121.88) pmol/L, $P=0.031)$ and following CRH (158.40 (34.32-275.00) vs 67.43 (8.8-179.52) $\mathrm{pmol} / \mathrm{L} P=0.016)$.

The time-dependent ACTH curves are showed in Fig. 3.

Baseline cortisol levels were superimposable between both groups. After $\mathrm{CRH}$, percent cortisol increment was lower in patients with ACC $(P=0.041)$.

\section{Discussion}

In the present study, we have thoroughly analyzed the HPA axis in 16 consecutive patients treated adjuvantly with mitotane at a stable dose following radical resection of ACC. The patients were free of tumor at the time of evaluation and showed no obvious clinical or biochemical sign of under- or over-dosing of glucocorticoid replacement. Patients treated adjuvantly with mitotane represent the best model to assess the clinical and biochemical alterations associated with mitotane use without confounding due to the systemic and endocrine effects of the tumor (16).

This study clearly shows that longstanding mitotane treatment almost invariably leads to adrenal insufficiency. Suppression of cortisol secretion was profound in most patients despite that a mitotane threshold $>14 \mathrm{mg} / \mathrm{L}$, which has been associated with the anti-neoplastic activity of the drug (19), was evident in only half of the patients. However, 9 of 11 patients with cortisol $<100 \mathrm{nmol} / \mathrm{L}$ had persistently elevated levels of mitotane in the previous determinations, showing that adrenal suppression cannot

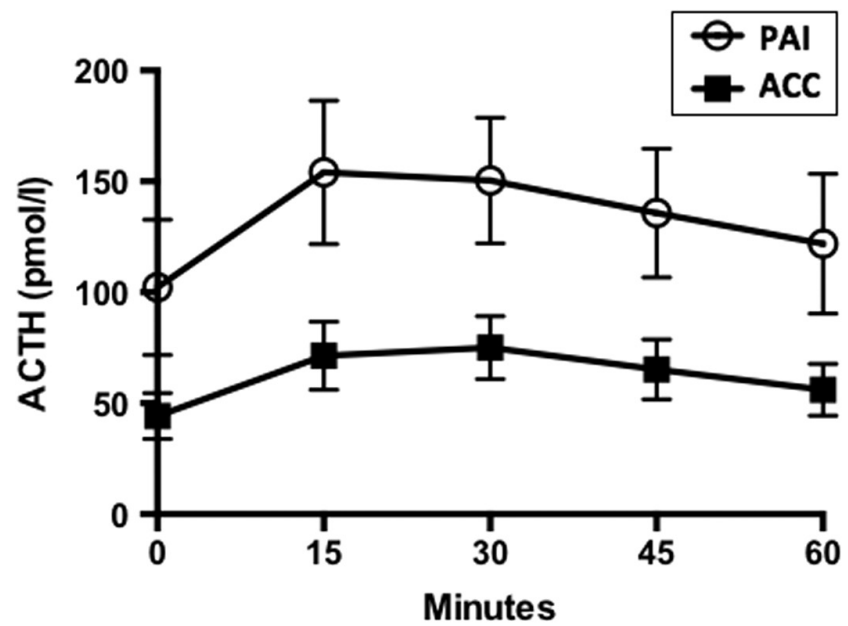

Figure 3

Comparison of time-dependent ACTH curves during CRH test between patients with ACC and patients with Addison disease. Data are expressed as mean +S.E.M.

be fully predicted by a single mitotane determination being more important the exposure to chronically elevated levels of mitotane. The present study also underlines how challenging it is to maintain mitotane concentrations in the therapeutic range (21).

We have also reported that mitotane enhances serum CBG levels $(16,22)$ and we have demonstrated a close correlation between CBG and mitotane levels. The mitotane-induced increase in CBG may partially mask the degree of cortisol suppression; thus, serum cortisol is generally regarded as an unreliable marker in mitotane-treated patients (22). Therefore, we have also assessed salivary cortisol in our patients, as cortisol levels in saliva reflect free cortisol (23) and may give a more accurate estimate of cortisol secretion independently from variation in CBG. Nevertheless, in our study the measurement of salivary cortisol did not add useful information for assessing adrenal insufficiency in mitotane-treated patients with ACC. This is probably due to high levels of cortisone in salivary samples, because of the remarkable expression

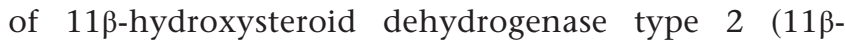
HSD2) in salivary epithelium cell (24). It is known that in RIA-based cortisol assays, specificity is affected from cross-reactivity between cortisol and cortisone (25). We have deliberately excluded urinary free cortisol (UFC) from hormonal assessment, as in mitotane-treated patients UFC assessment is unreliable because of the possible cross-reactivity of immunoassays with different metabolites, such as $6 \beta$-hydroxycortisol, whose urinary 
excretion is largely increased as a result of increased metabolic clearance of exogenous steroids on mitotane treatment (15). Our patients took a median daily dose of cortisone acetate, corresponding to $33.1 \mathrm{mg} / \mathrm{m}^{2}$ or $0.8 \mathrm{mg} / \mathrm{kg}$, which is higher than the median dose used in Addison's disease (26). It is current practice to use much elevated cortisol doses to replace adrenal insufficiency in mitotane-treated patients because mitotane induces a strong induction of cytochrome P4503A4, leading to inactivation of exogenous steroids (15). We are aware that cortisone acetate is not the best drug for steroid replacement, but it was the most readily available exogenous steroid in Italy in the past years (27).

Undetectable DHEAS levels in all patients may herald that $17 \alpha$-hydroxylase is particularly sensitive to mitotane inhibition, as it was shown in vitro (28). Conversely, we confirm that the zona glomerulosa is relatively spared by the cytotoxic effect of mitotane $(10,12)$, since a single patient needed mineralocorticoid replacement. However, assessment of the renin-aldosterone axis may be confounded by the current high-dose cortisol replacement.

ACTH levels were elevated in most but not all patients with ACC. However, ACTH median values were less increased at baseline and were less responsive to CRH stimulation in ACC than that in patients with PAI. We consider unlikely that the reduced rise of ACTH may be fully explained by the high-dose glucocorticoid replacement, as ACTH levels did not show any correlation with the dose of cortisone acetate over the previous 12 months. Therefore, the pattern of ACTH release following CRH stimulation may result from an inhibitory effect of mitotane on pituitary ACTH in agreement with previous in vitro data (17).

In conclusion, our results show that mitotane affects the HPA axis at multiple levels and some of the induced alterations may confound interpretation of hormone tests. Therefore, it is impossible to identify a single biomarker that is useful for the assessment of adrenal insufficiency and to guide hormone replacement in ACC patients treated with mitotane. The observation of lower ACTH levels in patients with ACC than that in patients with PAI, both in basal conditions and after CRH stimulation, suggests that mitotane may play an inhibitory effect on ACTH secretion at the pituitary level.

\section{Declaration of interest}

G R, S P, B Z, V B, L S, P P, S D F, M V, M C Z, S C have nothing to declare. $M T$ is on the advisory boards of Millendo Therapeutics and HRA Pharma.
Funding

Grant IG 2015-17678 from AIRC to M T.

\section{References}

1 Pommier RF \& Brennan MF. An eleven-year experience with adrenocortical carcinoma. Surgery 1992112 963-970.

2 Wajchenberg BL, Albergaria Pereira MA, Medonca BB, Latronico AC, Campos Carneiro P, Alves VA, Zerbini MC, Liberman B, Carlos Gomes G \& Kirschner MA. Adrenocortical carcinoma: clinical and laboratory observations. Cancer 200088 711-736. (doi:10.1002/ (SICI)1097-0142(20000215)88:4<711::AID-CNCR1>3.0.CO;2-W)

3 Dackiw AP, Lee JE, Gagel RF \& Evans DB. Adrenal cortical carcinoma. World Journal of Surgery 200125 914-926. (doi:10.1007/s00268-0010030-7)

4 Schteingart DE, Doherty GM, Gauger PG, Giordano TJ, Hammer GD, Korobkin M \& Worden FP. Management of patients with adrenal cancer: recommendations of an international consensus conference. Endocrine-Related Cancer 200512 667-680. (doi:10.1677/erc.1.01029)

5 Allolio B \& Fassnacht M. Clinical review: adrenocortical carcinoma: clinical update. Journal of Clinical Endocrinology and Metabolism 2006 91 2027-2037. (doi:10.1210/jc.2005-2639)

6 Libè R, Fratticci A \& Bertherat J. Adrenocortical cancer: pathophysiology and clinical management. Endocrine-Related Cancer 200714 13-28. (doi:10.1677/erc.1.01130)

7 Veytsman I, Nieman L \& Fojo T. Management of endocrine manifestations and the use of mitotane as a chemotherapeutic agent for adrenocortical carcinoma. Journal of Clinical Oncology 200927 4619-4629. (doi:10.1200/JCO.2008.17.2775)

8 Terzolo M, Angeli A, Fassnacht M, Daffara F, Tauchmanova L, Conton PA, Rossetto R, Buci L, Sperone P, Grossrubatscher E et al. Adjuvant mitotane treatment for adrenocortical carcinoma. New England Journal of Medicine 2007356 2372-2380. (doi:10.1056/NEJMoa063360)

9 Fassnacht M, Johanssen S, Fenske W, Weismann D, Agha A, Beuschlein F, Führer D, Jurowich C, Quinkler M, Petersenn S et al. Improved survival in patients with stage II adrenocortical carcinoma followed up prospectively by specialized centers. Journal of Clinical Endocrinology and Metabolism 201095 4925-4932. (doi:10.1016/j. yend.2011.06.050)

10 Fassnacht M, Kroiss M \& Allolio B. Update in adrenocortical carcinoma. Journal of Clinical Endocrinology and Metabolism 201398 4551-4564. (doi:10.1210/jc.2013-3020)

11 Else T, Williams AR, Sabolch A, Jolly S, Miller BS \& Hammer GD. Adjuvant therapies and patient and tumor characteristics associated with survival of adult patients with adrenocortical carcinoma. Journal of Clinical Endocrinology and Metabolism 201499 455-461. (doi:10.1210/jc.2013-2856)

12 Terzolo M, Daffara F, Ardito A, Zaggia B, Basile V, Ferrari L \& Berruti A. Management of adrenal cancer: a 2013 update. Journal of Endocrinological Investigation 201437 207-217. (doi:10.1007/s40618013-0049-2)

13 Ayala-Ramirez M, Jasim S, Feng L, Ejaz S, Deniz F, Busaidy N, Waguespack SG, Naing A, Sircar K, Wood CG et al. Adrenocortical carcinoma: clinical outcomes and prognosis of 330 patients at a tertiary care center. European Journal of Endocrinology 2013169 891-899. (doi:10.1530/EJE-13-0519)

14 Terzolo M \& Berruti A. Adjunctive treatment of adrenocortical carcinoma. Current Opinion in Endocrinology, Diabetes and Obesity 2008 15 221-226. (doi:10.1097/MED.0b013e3282fdf4c0)

15 Chortis V, Taylor AE, Schneider P, Tomlinson JW, Hughes BA, O'Neil DM, Libé R, Allolio B, Bertagna X, Bertherat J et al. Mitotane therapy in adrenocortical cancer induces CYP3A4 and inhibits $5 \alpha$-reductase, explaining the need for personalized glucocorticoid and androgen 
replacement. Journal of Clinical Endocrinology \& Metabolism 201398 161-171. (doi:10.1210/jc.2012-2851)

16 Daffara F, De Francia S, Reimondo G, Zaggia B, Aroasio E, Porpiglia F, Volante M, Termine A, Di Carlo F, Dogliotti L et al. Prospective evaluation of mitotane toxicity in adrenocortical cancer patients treated adjuvantly. Endocrine-Related Cancer 200815 1043-1053. (doi:10.1677/ERC-08-0103)

17 Gentilin E, Tagliati F, Terzolo M, Zoli M, Lapparelli M, Minoia M, Ambrosio MR, Degli Uberti EC \& Zatelli MC. Mitotane reduces human and mouse ACTH-secreting pituitary cell viability and function. Journal of Endocrinology 2013218 275-285. (doi:10.1530/ JOE-13-0210)

18 Zatelli MC, Gentilin E, Daffara F, Tagliati F, Reimondo G, Carandina G, Ambrosio MR, Terzolo M \& Degli Uberti EC. Therapeutic concentrations of mitotane (o, $\mathrm{p}^{\prime}$-DDD) inhibit thyrotroph cell viability and TSH expression and secretion in a mouse cell line model. Endocrinology 2010151 2453-2461. (doi:10.1210/en.2009-1404)

19 Hermsen IG, Fassnacht M, Terzolo M, Houterman S, den Hartigh J, Leboulleux S, Daffara F, Berruti A, Chadarevian R, Schlumberger M, Allolio B, Haak HR \& Baudin E. Plasma concentrations of o, p'DDD, $o, p^{\prime} \mathrm{DDA}$, and o, $\mathrm{p}^{\prime} \mathrm{DDE}$ as predictors of tumor response to mitotane in adrenocortical carcinoma: results of a retrospective ENS@T multicenter study. Journal of Clinical Endocrinology and Metabolism 201196 1844-1851. (doi:10.1210/jc.2010-2676)

20 De Francia S, Pirro E, Zappia F, De Martino F, Sprio AE, Daffara F, Terzolo M, Berruti A, Di Carlo F \& Ghezzo F. A new simple HPLC method for measuring mitotane and its two principal metabolites tests in animals and mitotane-treated patients. Journal of Chromatography B 2006837 69-75. (doi:10.1016/j. jchromb.2006.04.005)

21 Terzolo M, Zaggia B, Allasino B \& De Francia S. Practical treatment using mitotane for adrenocortical carcinoma. Current Opinion in Endocrinology, Diabetes and Obesity 201421 159-165. (doi:10.1097/ med.0000000000000056)
22 Alexandraki KI, Kaltsas GA, le Roux CW, Fassnacht M, Ajodha S, Christ-Crain M, Akker SA, Drake WM, Edwards R, Allolio B et al. Assessment of serum-free cortisol levels in patients with adrenocortical carcinoma treated with mitotane: a pilot study. Clinical Endocrinology 201072 305-311. (doi:10.1111/j.13652265.2009.03631.x)

23 Nieman LK, Biller BM, Findling JW, Newell-Price J, Savage MO, Stewart PM \& Montori VM. The diagnosis of Cushing's syndrome: an Endocrine Society Clinical Practice Guideline. Journal of Clinical Endocrinology and Metabolism 200893 1526-1540. (doi:10.1210/ jc.2008-0125)

24 Smith RE, Maguire JA, Stein-Oakley AN, Sasano H, Takahashi KI, Fukushima K \& Krozowski ZS. Localization of $11 \beta$-hydroxysteroid dehydrogenase type II in human epithelial tissues. Journal of Clinical Endocrinology and Metabolism 199681 3244-3248. (doi:10.1210/ jcem.81.9.8784110)

25 Vieira JG, Nakamura OH \& Carvalho VM. Determination of cortisol and cortisone in human saliva by a liquid chromatography-tandem mass spectrometry method. Arquivos Brasileiros de Endocrinologia and Metabologia 201458 844-850. (doi:10.1590/00042730000003347)

26 Bornstein SR, Allolio B, Arlt W, Barthel A, Don-Wauchope A, Hammer GD, Husebye ES, Merke DP, Murad MH, Stratakis CA et al. Diagnosis and treatment of primary adrenal insufficiency: an endocrine society clinical practice guideline. Journal of Clinical Endocrinology and Metabolism 2016101 364-389. (doi:10.1210/jc.2015-1710)

27 Laureti S, Falorni A \& Santeusanio F. Improvement of treatment of primary adrenal insufficiency by administration of cortisone acetate in three daily doses. Journal of Endocrinological Investigation 200326 1071-1075. (doi:10.1007/BF03345252)

28 Lehmann TP, Wrzesinski T \& Jagodzinski PP. The effect of mitotane on viability, steroidogenesis and gene expression in NCI-H295R adrenocortical cells. Molecular Medicine Reports 20137 893-900. (doi:10.3892/mmr.2012.1244)

Received 4 June 2017

Revised version received 24 July 2017

Accepted 31 July 2017 